\title{
STEM stereotypes predict students' STEM career interest via self-efficacy and outcome expectations
}

\author{
Tian Luo ${ }^{1} \mathbb{D}$, Winnie Wing Mui So ${ }^{1 *} \mathbb{D}$, Zhi Hong Wan²] and Wai Chin Li ${ }^{1} \mathbb{D}$
}

\begin{abstract}
Background: Nurturing students' interest in science, technology, engineering, and mathematics (STEM) careers is a major goal of STEM education. Although the relationship between students' stereotypical beliefs regarding STEM careers and their career interest can be reasonably hypothesized, research investigating the extent to which and how students' STEM career interest is directly or indirectly influenced by their stereotypical beliefs is lacking. This study investigated how upper primary students' stereotypical beliefs regarding STEM careers predicted their STEM self-efficacy and STEM career-related outcome expectations and how these constructs predicted their STEM career interest. Structural equation modelling was used to analyse quantitative survey data of 824 fourth- to sixth-grade students and test the hypothesized models.

Results: Students' stereotypical beliefs regarding STEM careers negatively predicted their self-efficacy in STEM activities and career-related outcome expectations. Additionally, the students' self-efficacy in STEM activities and career-related outcome expectations in turn predicted their STEM career interest.

Conclusions: These results explain the potential indirect effect of STEM stereotypes on students' career interest through self-efficacy and outcome expectations. The findings highlight the significant role of STEM stereotypes, selfefficacy in STEM activities, and career-related outcome expectations in students' career development. The implications of this study for STEM education are also discussed.
\end{abstract}

Keywords: STEM career interest, Stereotypes, Self-efficacy, Outcome expectations, SEM

\section{Introduction}

Internationally, the low percentage of enrolment and participation in science, technology, engineering, and mathematics (STEM) career paths has been a concern in many countries and regions (Marginson et al., 2013; Organization for Economic Co-operation and Development, 2008). In this context, the promotion of STEM education in many nations and regions has involved an effort to nurture students' interest in and intention to

\footnotetext{
* Correspondence: wiso@eduhk.hk

'Department of Science and Environmental Studies and Centre for Education in Environmental Sustainability, The Education University of Hong Kong, 10 Lo Ping Road, Tai Po, Hong Kong, People's Republic of China

Full list of author information is available at the end of the article
}

pursue STEM careers. STEM education is realized as not only separate disciplines but also as an integrated curriculum (National Research Council, 2014; Office of the Chief Scientist, 2014). Formal and informal integrated STEM education have also been promoted and implemented (Education Bureau, Hong Kong, 2016; Japan Society for STEM Education, 2018; So et al., 2018) as integrated STEM learning provides opportunities for students to engage in real-context problem-solving and enables students to flexibly apply knowledge and skills in science, technology, engineering, and mathematics.

Educators and researchers have noticed that the STEM career trajectory is similar to an ever-narrowing pipeline, with increasingly fewer students interested in STEM from lower to higher grades (Metcalf, 2010). At the

\section{Springer Open}

(c) The Author(s). 2021 Open Access This article is licensed under a Creative Commons Attribution 4.0 International License, which permits use, sharing, adaptation, distribution and reproduction in any medium or format, as long as you give appropriate credit to the original author(s) and the source, provide a link to the Creative Commons licence, and indicate if changes were made. The images or other third party material in this article are included in the article's Creative Commons licence, unless indicated otherwise in a credit line to the material. If material is not included in the article's Creative Commons licence and your intended use is not permitted by statutory regulation or exceeds the permitted use, you will need to obtain permission directly from the copyright holder. To view a copy of this licence, visit http://creativecommons.org/licenses/by/4.0/. 
individual level, it could be beneficial to analyse this issue through the lens of career development, which is an important life-long process for all individuals. From the career development perspective, STEM education has the potential to provide experiences and careerrelated information for individuals to consider when they need to make career decisions. Thus, it is necessary to understand how students develop an interest in or reject STEM careers. Stereotypes regarding STEM careers represent an important influential factor in STEM career interest (Archer et al., 2013; DeWitt et al., 2013; van Tuijl \& van der Molen, 2016). However, the mechanism and extent of the influence of stereotypes on STEM career interest have not been well explored.

\section{Stereotypes regarding STEM careers and students' career interest}

Stereotypes are over-generalized beliefs regarding a group of people that are often negative (Matsumoto, 2009; VandenBos,, \& American Psychological Association, 2015). STEM stereotypes are stereotypes regarding people working in STEM fields. Students' STEM stereotypes have long been discussed in the educational literature. Previous studies have found that students hold stereotypes of scientists and engineers and their work (Capobianco et al., 2011; Fralick et al., 2009; Lachapelle et al., 2012). Additionally, Hong Kong elementary and secondary students have been found to hold similar stereotypes of scientists to those held by students in the West (Fung, 2002). Furthermore, the stereotypes held against scientists, engineers, and technologists among upper-elementary students in Hong Kong were found to be prevalent (Luo et al., 2018). In addition, some researchers found that middle school students have limited knowledge regarding the work of STEM professionals and their subject requirements (Blotnicky et al., 2018). According to surveys and information collected in Organization for Economic Co-operation and Development (OECD) countries, students generally view professionals in science and technology as "doing boring, uninteresting work in unpleasant surroundings, cut off from other people" (Organization for Economic Co-operation and Development (OECD), 2008). Similarly, Masnick et al. (2010) assessed high school students' perceptions of a range of STEM and nonSTEM careers and found that high school and college students perceived STEM careers as less peopleoriented and less creative than non-STEM careers.

The science education literature suggests that students' STEM stereotypes may have a negative influence on their STEM career interest (Archer et al., 2013; DeWitt et al., 2013; van Tuijl \& van der Molen, 2016). Regarding career development theories, Gottfredson
(1981) argued that occupational stereotypes can influence individuals' process of narrowing down their career choices. Nassar-McMillan et al. (2011) noted that stereotypes regarding a career may influence the perceived match between the individual and the career. Archer et al. (2013) found in interviews with parents that students sometimes rejected science as a career choice because they held the stereotype that people in science careers are "geeks" or "boffins". A qualitative study showed that some students viewed science as being for "specialists" or "not for me" and excluded science as a potential career choice (DeWitt et al., 2013). Archer et al. (2013) argued that the perceptions of people with science careers as "clever/brainy", "not nurturing", and "geeky" held by upper-elementary students prevented female students from aspiring to science careers. As summarized in a review article by van Tuijl and van der Molen (2016), students' STEM stereotypes are considered a problem that needs to be addressed.

Although the effect of STEM stereotypes on students' career interest (possibly an indirect one) can be reasonably hypothesized, research investigating the extent to which and how students' STEM career interest is influenced by their STEM stereotypes is lacking. This lack of research is the major gap to be filled in this study.

\section{STEM stereotypes and their associations with career interest through self-efficacy and outcome expectations} STEM stereotypes may be related to students' career interest through both self-efficacy and outcome expectations. The relationships among self-efficacy, outcome expectations, and STEM career interest have received much theoretical and empirical support, while the effect of STEM stereotypes on self-efficacy, outcome expectations, and STEM career interest remains unclear.

\section{Self-efficacy, outcome expectations, and STEM career interest}

The relationships among self-efficacy, outcome expectations and career interest have been well explored as the key constructs in a widely accepted career development theory called social cognitive career theory (SCCT). Selfefficacy, which was first conceptualized by Bandura (1977), refers to individuals' "beliefs about their capabilities to produce effects". Self-efficacy has been found to predict students' level of effort, choices, and persistence in learning (Zimmerman, 2000). More specifically, STEM self-efficacy refers to students' beliefs regarding their abilities to perform STEM learning activities. Outcome expectations are defined as the expected results of a particular action (i.e., the expected answer to the question "If I do this, what will happen?") (Bandura, 1977, 
1986; Lent et al., 1994). In the present study, STEM career interest is defined as individuals' general interest in choosing STEM-related careers (such as careers as scientists, engineers, or technologists) in the future. Career interest is similar to (but weaker than) career aspirations and should be positioned alongside choice/goals in the SCCT model.

Career-related goals are influenced by self-efficacy and outcome expectations and outcome expectations are also predicted by self-efficacy in SCCT (Lent et al., 2002, 2015). The associations among these constructs, as shown in Fig. 1, were proposed based on the social cognitive theory developed by Bandura (1986) and were further developed by Lent et al. $(2002,2015)$. According to a review by Betz (2008), the SCCT model has been widely accepted and applied in empirical research in the social science fields, including in STEM education (Lin \& Deemer, 2019; van Tuijl \& van der Molen, 2016). According to a meta-analysis performed by Lent et al. (2018) using data from 143 studies, the SCCT choice model has been applied in disciplinary STEM education, and the relationships among self-efficacy, outcome expectations, and career interest have received support overall.

However, fewer studies tested the relationships among self-efficacy, outcome expectations, and career interest from an integrated STEM perspective (Nugent et al., 2015; van Aalderen-Smeets et al., 2018). Nugent et al. (2015) found that in a crosssectional study that 10 - to 14-year-old students' STEM interest predicted their STEM self-efficacy and outcome expectations. Moreover, STEM self-efficacy contributed to the students' STEM knowledge learning and problem-solving, while outcome expectancy further contributed to their STEM career orientation. In Nugent et al.'s (2015) model, interest is a predictor of self-efficacy and outcome expectancy, which is in the reverse direction of the relationship compared to that proposed in the SCCT model.
STEM stereotypes, STEM self-efficacy, and STEM outcome expectations

STEM stereotypes are conceptualized as a background contextual affordance (or barrier) in this study. STEM stereotypes, namely the perceived stereotypical images of STEM professionals/career options, can be viewed as a part of the perceived societal environment. Lent et al. (2000) argued that perceived environmental factors can influence individuals' career development by shaping the experiences that influence self-efficacy and outcome expectations. As argued by Garriott et al. (2016) and Hancock et al. (2020), according to the SCCI framework, STEM stereotypes were conceptualized as a background contextual affordance in their quantitative study.

STEM self-efficacy and outcome expectations not only were shown to predict career interest, but also might be predicted by STEM stereotypes. Therefore, these two factors are hypothesized to be mediating factors in the model in this study. The mechanism of the effect of STEM stereotypes on STEM self-efficacy may be that a stereotypical view of STEM professionals provokes the perception of dissimilarity between the self and career. As shown in a study by Cheryan et al. (2011), a perceived dissimilarity to stereotypical STEM professionals predicted female undergraduate students' perceived success in computer science, suggesting that STEM stereotypes may prevent students from developing STEM selfefficacy.

Theoretically, it can be logically inferred that people who hold negative stereotypes regarding STEM careers may also tend to expect negative outcomes in STEM careers. In other words, students' STEM career-related outcome expectations may be consistent with their views of STEM careers, including stereotypes. For example, in Holmegaard et al. (2014) qualitative study, a student who was interested in technical engineering but held negative stereotypes of engineers had negative outcome expectations of being an engineer as working in isolation.

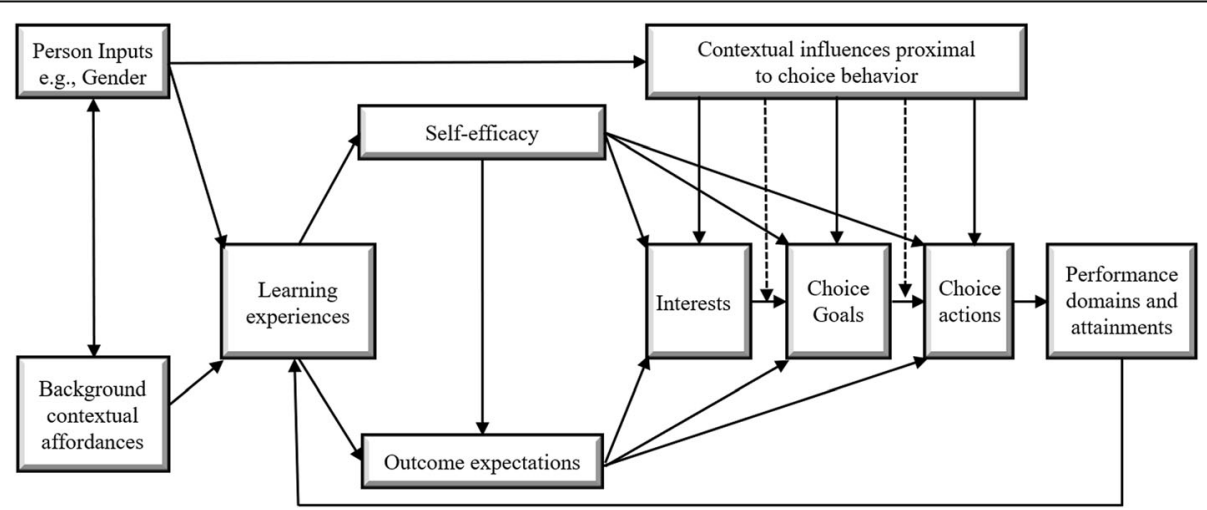

Fig. 1 The choice model of social cognitive career theory (adapted from Lent et al., 2002) 
Garriott et al. (2016) found that high school students' STEM stereotypes significantly predicted their mathematics/science self-efficacy and interest, which in turn predicted their career goals. The instrument used to assess STEM stereotypes used in the study was the Math and Science Stigma (MASS) Scale, which focuses on students' stereotypical perceptions of people who work in STEM fields in general. For example, in the MASS Scale, students are asked whether they think people working in STEM fields "are weird" or "have poor social skills".

\section{Hypothesized model in this study}

To close the research gap regarding how and the extent to which STEM stereotypes influence students' career interest through self-efficacy and outcome expectations, the following research question is proposed: what are the associations among elementary students' STEM stereotypes, STEM self-efficacy, STEM outcome expectations, and STEM career interest?

To answer the research question, the hypothesized model is tested (Fig. 2). First, in this study, STEM is used to represent general learning in science, technology, engineering, and mathematics, with an emphasis on integrated STEM learning. Integrated STEM learning refers to learning in which the knowledge and skills learned from STEM disciplines are applied to real-world problems or projects. The integrated STEM learning perspective is emphasized in this study because (1) this perspective can better reflect the nature of real-world challenges in STEM careers (Johnson, 2013); (2) this perspective can better capture the nature of STEM learning among upper-elementary students in Hong Kong as they regularly participate in STEM projectbased learning, in which science, technology, engineering, and mathematics are naturally connected (So et al., 2018); and (3) previous related studies (Garriott et al.,
2016; Nugent et al., 2015; Shen et al., 2014) have not fully addressed the role of integrated STEM learning in students' career development.

Consistent with the emphasis on integrated STEM learning, the instrument used to assess STEM selfefficacy focuses on students' self-efficacy in STEM activities, which reflect the nature of STEM professionals' daily work. The other three key constructs, namely, STEM stereotypes, outcome expectations, and career interest, are closely related to STEM careers. Here, STEM careers refer to careers in which people integrate science, technology, engineering, and mathematics into their work to a large degree (e.g., scientists, engineers, and technologists).

In the proposed model (Fig. 2), the associations among self-efficacy, outcome expectations, and career interest are consistent with the SCCT model and many previous empirical studies (Lent et al., 2015, 2018). In addition, based on theoretical and empirical evidence from the literature review, the indirect negative effects of STEM stereotypes on career interest through self-efficacy and outcome expectations and the direct negative effect of STEM stereotypes on career interest are added to the model.

Because support in the literature for the indirect effects (STEM stereotypes $\rightarrow$ self-efficacy $\rightarrow$ career interest and STEM stereotypes $\rightarrow$ outcome expectations $\rightarrow$ career interest) and direct effect of STEM stereotypes on STEM career interest is scarce, some nested models within model A are also plausible and worth exploring. Regarding these potential models, as the associations among self-efficacy, outcome expectations, and career interest in STEM learning have received much theoretical and empirical support, the associations among these three constructs were set as fixed. Thus, in addition to model A, a model with one or two of the three paths

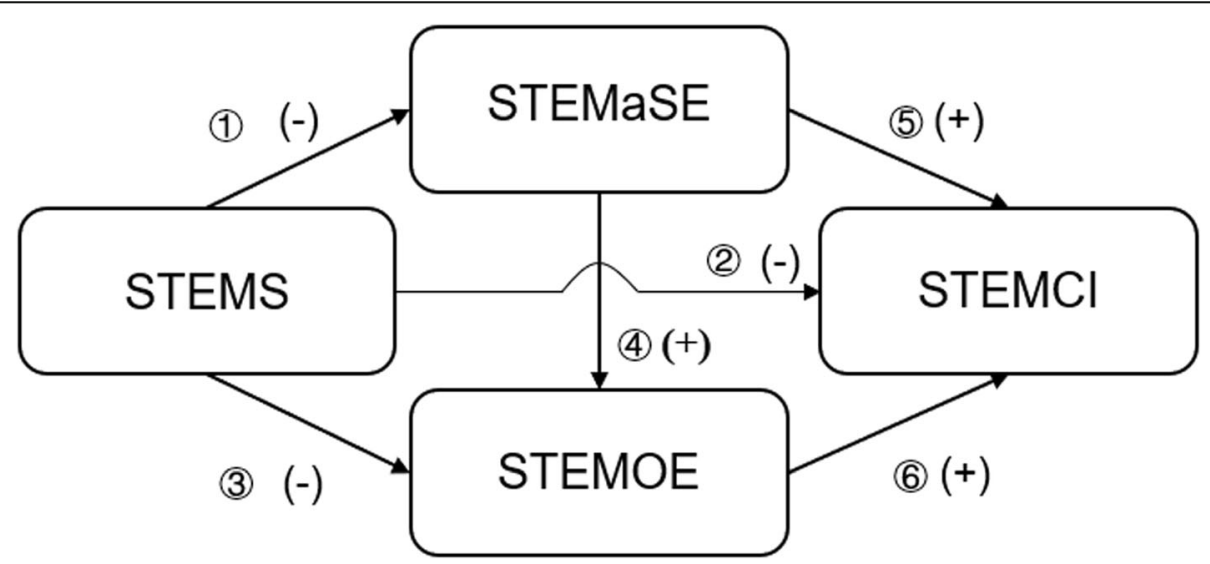

Fig. 2 Hypothesized model A (STEMS refers to STEM stereotypes, STEMaSE refers to self-efficacy in STEM activities, STEMOE refers to STEM outcome expectations, and STEMCI refers to STEM career interest. The paths are numbered. For example, path (1) indicates the path from STEM stereotypes to self-efficacy in STEM activities) 
among path (1), (2), and (3) and all remaining paths (path (4), (5) and (6) in Fig. 2 may also be valid.

\section{Methods}

To measure STEM stereotypes, STEM self-efficacy, STEM career-related outcome expectations, and career interest, instruments were developed, translated and/or revised, and validated through a set of processes. To test the hypothesized model, the data were then analysed through structural equation modelling (SEM).

\section{Sample}

The formal sample included fourth- to sixth-grade students in intact classes from four government-aided elementary schools located in four different districts in Hong Kong. All Hong Kong elementary schools receive yearly government funding for STEM education, and the four schools provide students (grades 4 to 6) with experience in STEM activities. After informed consent was obtained from the students and their parents, the teachers administered the anonymous paper-based surveys to the students in the classrooms. The data were input and recoded with SPSS 25.0. Cases with over 60\% responses that were blanks/invalid, or with obvious response patterns, such as repeating $\mathrm{B}, \mathrm{C}, \mathrm{B}$, and $\mathrm{C}$ throughout the questionnaire were deleted. The ages of the participating students ranged from 6 to $14(M=$ $10.2, \mathrm{SD}=1.02)$. The demographic summary of the valid sample $(n=824)$ is shown in Table 1.

\section{Item pool development}

In this study, all survey instruments are in Chinese. The measure of STEM stereotypes (STEMS) was translated from the MASS Scale. The measures of self-efficacy in STEM activities (STEMaSE), STEM career-related outcome expectations (STEMOE), and STEM career interest (STEMCI) were self-developed.

\section{STEM stereotypes (STEMS)}

The MASS Scale was developed by Garriott et al. (2016) and used as a measure of STEM stereotypes. The initial version was developed by experts in career development and validated with 341 high school students; eight items were retained to form a single-factor instrument. In their study, the 8-item version of the MASS Scale was validated using a confirmatory factor analysis with 358 students, and its single-factor structure was confirmed with a Cronbach's alpha of .93. Four of the eight items focus on the "less people-oriented" aspect of STEM stereotypes, echoing the findings of Masnick et al.'s (2010) study.

In this study, the MASS Scale was translated and slightly simplified such that fourth- to sixth-grade students could fully understand the items. The scale was translated by the researcher, who is a native speaker of Chinese and fluent in English. The translated scale was examined by another researcher in this study. The Chinese version was then translated back into English by a Chinese graduate majoring in English. Then, the translated items and the original items were compared by an English native speaker who is a Ph.D. student in science to ensure that the meaning of the translated items was consistent with that of the original items. Two items (e.g., "people doing STEM-related jobs always do physical labour" and "people doing STEM-related jobs need to move heavy things, fix and build") were added to the STEMS instrument based on the results of another study conducted by the researchers (Luo et al., 2018), which shows that students tend to relate engineers to labour work, mostly in construction.

\section{STEM self-efficacy in STEM activities (STEMaSE)}

Some measures of STEM self-efficacy with an emphasis on the integrated features of STEM education are available (Milner et al., 2014; Nugent et al., 2010; van Aalderen-Smeets et al., 2018). However, these instruments are either area-specific (e.g., robotics and GPS/

Table 1 Demographics of the sample

\begin{tabular}{llll}
\hline & & Participants & Percentage in valid sample (\%) \\
\hline School & School A & 209 & 25.4 \\
& School B & 166 & 20.1 \\
& School C & 299 & 36.3 \\
& School D & 150 & 18.2 \\
Grade (valid) & 4th & 247 & 30.8 \\
& 5th & 290 & 36.2 \\
Gender (valid) & 6th & 265 & 33.0 \\
& Male & 407 & 50.8 \\
Total & Female & 394 & 49.2 \\
\hline
\end{tabular}


GIS learning) or more suitable for high school or college students (e.g., with phrases such as "measuring the speed of electrons", or abstract phrases such as "skills taught in STEM classes").

The STEMaSE instrument was developed to measure student' self-efficacy in STEM activities (refer to the work by Luo et al. (2020) regarding the development and validation of the instrument). The item pool was developed based on the published framework of STEM learning developed by So et al. (2018). Then, the item pool was reviewed by two researchers in science education to ensure that the items follow the definition of self-efficacy in STEM activities.

\section{STEM outcome expectations (STEMOE)}

Here, the term "STEM outcome expectations" refers to STEM career-related outcome expectations, i.e., the expected outcomes of STEM occupations. A few measures for career-related outcome expectations exist. For example, the measure used by Hazari et al. (2010) in their study examines students' general career-related outcome expectations that are not specific to STEM domains. The STEMOE items used in this study were newly developed and focused on social career-related outcome expectations. The STEMOE items (e.g., "If I do STEMrelated jobs, I can help others") were developed based on the literature review, the researchers' life experiences, and informal discussions with students in the fourth to sixth grade. The item pool was developed by the first author, and then, the items were selected for further expert review by two researchers in science education.

\section{STEM career interest (STEMCI)}

Previous instruments used to assess STEM career interest measured a spectrum of constructs, such as intention to enter certain STEM careers (Sadler et al., 2012), career-related attitudes towards STEM careers (Kier et al., 2014), and interest in (entering) STEM careers (Diekman et al., 2010; Oh et al., 2013). Diekman et al.'s (2010) measure of career interest only includes four items related to STEM careers, and each item refers to a single STEM occupation (e.g., industrial engineer). The Educational and Career Interest in STEM measure developed by Oh et al. (2013) also approaches the concept of STEM career interest as interest in entering STEM careers, which is similar to the conceptualization in this study. However, their instrument treats STEM as isolated disciplines, and each item addresses one discipline, while there are no items related to engineering. Therefore, to assess students' general interest in choosing STEM careers, a new instrument was developed (e.g., "I hope my future job could be related to STEM"). The item pool was based on a review of other instruments in the literature and informal discussion with fourth- to sixth-grade students. Five items were selected from the item pool for further review by two researchers in science education.

\section{Expert review and student interviews}

The translated/revised instrument items were then added to the selected items and reviewed by three researchers in STEM education, including two researchers in STEM education working at a university and one Ph.D. student in mathematics education with elementary teaching experience. The definitions of the measured constructs were given to the reviewers, and the reviewers were asked whether the items targeted the construct and whether they thought the items would be well understood by fourth- to sixth-grade students. The reviewers were also encouraged to provide comments regarding the items to identify items with a lower face validity for subsequent revision or deletion.

Two groups of fourth- to fifth-grade Hong Kong students (total $n=17$ ) participated in group interviews to ensure that the wording of the items was easily understandable. After finishing the surveys, the students were invited to share anything that they were confused about and their interpretations of the survey items. The interviewer also explained the items or phrases if students had confusion. Afterwards, students were encouraged to provide alternative wording that they thought was more understandable. During the interviews, the students tended to view STEM/STEM careers as terms referring to a series of STEM-related disciplines and activities/careers. Additionally, the students' interpretations of the items were generally aligned with the target constructs, except for some items, which were revised after the interviews.

\section{Pilot test}

The instruments were then piloted with 111 fourth- to sixth-grade students participating in a STEM fair. Students who consented to participate in the survey investigation completed the paper-based surveys. Based on the data analysis and evaluation of the indices, such as through the calculation of item-total correlations, no item was deleted. The Cronbach's alphas of the instruments ranged from 0.803 to 0.897 .

\section{Data analysis}

After the data were collected from the sample $(n=824)$, an exploratory factor analysis (EFA) and a confirmatory factor analysis (CFA) were conducted to validate each instrument. The EFA helped identify whether each instrument had the hypothesized internal structure (dimensionality) and provided evidence of the validity of each instrument. The number of factors extracted was based on both screen plot and eigenvalues. Then, the 
resulting factor structure of each instrument was then analysed by CFA using the SEM technique.

SEM is a very powerful method used to conduct multiple regressions simultaneously (Pedhazur, 1997). SEM allows for the testing of hypotheses regarding how constructs are associated with one another (Schreiber et al., 2006). SEM was applied in this study for two purposes. First, the measurement model of each instrument from the CFA was tested. Second, the structural model was used to determine which of the proposed models was the most suitable for describing the data. To evaluate the model fit for both purposes, absolute indices, including $X^{2}$ and $\chi^{2} / \mathrm{df}$ (as the model $\chi^{2}$ is easily influenced by the sample size, the CMIN/df is also reported), and incremental fit indices were calculated as goodness-of-fit indices for the SEM analysis.

For the evaluation of the model fit of the measurement model (for the CFA) and structural model, the criteria for the goodness-of-fit indices are explained as follows. According to Wheaton (1987), the CMIN/df should be lower than 5, the comparative fit index (CFI) should be larger than 0.95 (Hu \& Bentler, 1999), the standardized root mean square residual (SRMR) should be smaller than 0.08 (Hu \& Bentler, 1999), the root mean square error of approximation (RMSEA) should be smaller than 0.08 to indicate a close fit (Browne \& Cudeck, 1993), the goodness-of-fit index (GFI) should be larger than 0.9 (Jöreskog \& Sörbom, 1996), the normed fit index (NFI) should be larger than 0.9 (Bentler \& Bonett, 1980), the incremental fit index (IFI) should be no smaller than 0.95, and the Tucker-Lewis index (TLI) should be no smaller than 0.95 (Schreiber et al., 2006). When interpreting these indices, the CFI, SRMR, and RMSEA were considered priority indices as they are more robust to type II error.

As suggested by Hair (2006), a factor analysis should be applied by conducting an EFA and a CFA with separate samples and comparing the results to ensure statistical robustness. Thus, the sample was randomly divided into two subsamples, namely, sample I and sample II, for the EFA and CFA, respectively. An EFA with oblimin rotation was conducted on sample I $(n=410)$ using SPSS. A CFA was conducted on sample II $(n=414)$ using AMOS. The Cronbach's alphas and other item statistics were also calculated. Missing data were treated using the maximum likelihood estimator as recommended by Allison (2003) and Hair (2006).

After the evaluation of the EFA and CFA results, item deletion and model modification, the instruments were finalized, and the Cronbach's alpha values were calculated. The structural model was applied to the data $(n=$ 824) through SEM to test the hypothesized models. To compare the plausible models, the $\chi^{2}$ difference test was applied to model $\mathrm{A}$ and its nested models. If the $\chi^{2}$ difference test showed no significant difference between the models, indicating that the compared models explained the data equally well, the simpler models could be chosen due to better parsimony. In addition, parsimonious fit indices including, the adjusted goodness-of-fit index (AGFI) and the Akaike information criterion (AIC), were adopted to compare the models, as suggested by Schermelleh-Engel et al. (2003), with larger AGFI and smaller AIC values indicating a better model fit.

The standardized and unstandardized direct effects in the model and the indirect effects of STEM stereotypes on STEM career interest were calculated in the finalized model. The significance of the total indirect effect of STEM stereotypes on STEMCI and the specific indirect effects were tested using bootstrapping procedures. The unstandardized indirect effects were computed for each of 2000 bootstrapped samples, and the $95 \%$ confidence interval was adopted to determine the indirect effects at the 2.5th and 97.5th percentiles.

\section{Results}

\section{Instrument validation}

The item ratings all fell within a reasonable range (1-5), and the skewness and kurtosis of the items ( -3 to 3 ) showed fair normality (Kline, 2005). Bartlett's test of sphericity and the Kaiser-Meyer-Olkin (KMO) measures indicated the suitability of performing an EFA of all four instruments.

\section{STEM stereotypes}

After several rounds of EFA and CFA, four items were deleted because of low factor loadings or a poor model fit. The four deleted items included two newly added items and two items from the original scale ("are not good athletes" and "spend all their time alone"). The factor loadings of each item in the EFA ranged from 0.678 to 0.876 , and the communalities ranged from 0.459 to 0.767 . The initial eigenvalue was 3.693 , which explained $61.552 \%$ of the total variance. The CFA confirmed that the data fit the one-dimensional model well after the deletion of the four items, which is consistent with the original factor structure (Garriott et al., 2016). The standardized regression weights in the CFA ranged from 0.671 to 0.819 . The fit indices of the CFA results are shown in Table 2 and indicated that the data fit the model well. The finalized six-item instrument had a Cronbach's alpha of .881.

\section{Self-efficacy in STEM activities (STEMaSE)}

According to the EFA results, the STEMaSE instrument exhibited a one-factor structure with an initial eigenvalue of 5.442 , explaining $45.348 \%$ of the total variances. The EFA factor loadings of the items ranged from 0.449 
Table 2 Fit indices of the SEM measurement (CFA) models of the instruments

\begin{tabular}{|c|c|c|c|c|c|c|c|c|c|c|c|}
\hline & \multicolumn{7}{|c|}{ Absolute fit indices } & \multicolumn{4}{|c|}{ Incremental fit indices } \\
\hline & $x^{2}$ & Df & $p$ & $x^{2} / \mathrm{df}$ & GFI & SRMR & RMSEA & $\overline{\mathrm{NFI}}$ & CFI & IFI & TLI \\
\hline STEM stereotypes & 29.554 & 9 & $p<.01$ & 3.284 & .977 & .0253 & .074 & 976 & .983 & .983 & .972 \\
\hline STEMaSE & 88.857 & 41 & $p<.001$ & 2.167 & .967 & .0289 & .053 & .960 & .978 & .978 & .964 \\
\hline STEMOE & .510 & 1 & $p=.475$ & .510 & .999 & .0048 & .000 & .999 & 1.000 & 1.001 & 1.004 \\
\hline STEMCI & 14.259 & 5 & $p<.05$ & 2.852 & .987 & .0160 & .067 & .989 & .993 & .993 & .986 \\
\hline
\end{tabular}

to 0.760 , and the communalities ranged from 0.202 to 0.578 , which is above the communality criteria of 0.2 suggested by Child (2006). As there were some similar phrases among several items, errors were set as correlated among items. The regression weights of the items in the CFA ranged from 0.445 to 0.787 , and the Cronbach's alpha for the instrument was .893 . The CFA results (Table 2) supported the one-factor structure of the 12-item instrument.

\section{STEM outcome expectations (STEMOE)}

During the initial rounds of the EFA and CFA, item 5 in the STEMOE instrument ("If I do STEM-related jobs, I can be respected by others") was deleted to obtain a better model fit. In addition, because items 3 and 4 had similar phrasing and sentence structure, correlated errors were allowed between these two items in the CFA. The STEMOE instrument was then found to have a one-factor structure in both the EFA and CFA. The factor loadings of each item in the EFA ranged from 0.646 to 0.881 with an initial eigenvalue of 2.511 , explaining $62.775 \%$ of the total variance, and communality range of 0.417 to 0.776 . The standardized regression weights in the CFA ranged from .570 to .890 . Except for the model $\chi^{2}$, which is easily influenced by large sample sizes, all other fit indices (Table 2) showed that the data fit the one-factor CFA model well. The finalized four-item instrument had a Cronbach's alpha of .812 .

\section{STEM career interest (STEMCI)}

The EFA showed that the five-item STEMCI instrument has a one-factor solution, and the CFA results confirmed that the data fit the one-factor model well. Therefore, no item needed to be deleted. The five-item instrument had a Cronbach's alpha of .902 . The initial eigenvalue was 3.581 , which explained $71.618 \%$ of the total variance. The communalities ranged from 0.629 to 0.806 and the factor loadings of each item in the EFA ranged from 0.793 to 0.898 . The standardized regression weights in the CFA ranged from .691 to .916 . The CFA model fit indices are shown in Table 2.

In summary, all four instruments were found to have one factor according to both the EFA and CFA. The final Cronbach's alphas of all instruments ranged from .812 to .902. All items of the four instruments are provided in Appendix 1. All means, standard deviations (SDs), and correlations among the constructs can be found in Appendix 2.

\section{Testing and comparing the models}

Model A (see Figs. 2 and 3) was tested first using SEM. According to the results, the students' STEM stereotypes in this model are not significantly related to their STEM career interest (standardized coefficient $=-.061, p=$ $.085)$, suggesting that model A needed to be compared with its nested model without the direct effect of STEM stereotypes on career interest. Then, the $\chi^{2}$ difference test was used to compare model A and model B (see Fig. 3 ). The $\chi^{2}$ difference test showed no significant differences between models $\mathrm{A}$ and $\mathrm{B}$, with $\chi^{2}=2.959, \mathrm{~d} f=1$, $p=.085$, suggesting that models $\mathrm{A}$ and $\mathrm{B}$ fit the data equally well. The evidence from the $\chi^{2}$ difference test, the nonsignificant coefficient of STEM stereotypes $\rightarrow$ STEM career interest in model A and the similar AIC and AGFI indices (Table 3) between models $\mathrm{A}$ and $\mathrm{B}$ suggested that model A cannot explain the data better than model B. For parsimony reasons, model B should be chosen over model $\mathrm{A}$.

Similarly, model B should be compared to its nested models to determine which model has greater parsimony. The $\chi^{2}$ difference test for nested models demonstrated a significant difference between model B and its two nested models, C and D (see Fig. 3). The comparison of models $\mathrm{B}$ and $\mathrm{C}$ yielded $\chi^{2}=22.096, \mathrm{~d} f=1$, and $p$ $<.001$, and the comparison of models B and D yielded $\chi^{2}=27.087, \mathrm{~d} f=1$, and $p<.001$. In addition, according to the parsimony fit indices, model $\mathrm{B}$ had a higher AGFI $(\mathrm{AGFI}=.916)$ than model $\mathrm{C}(\mathrm{AGFI}=.914)$ and model $\mathrm{D}$ $(\mathrm{AGFI}=.914)$ and model $\mathrm{B}$ had a lower AIC (AIC = 934.763) than model $C($ AIC $=954.860)$ and model D $($ AIC $=959.850)$; these findings suggest that model B has a better fit than models $C$ and $D$. In general, the other goodness-of-fit indices of hypothesized model B were also optimal compared to those of models $\mathrm{C}$ and $\mathrm{D}$ (Table 3). For example, the CFI of model B was 0.002 higher than that of models $\mathrm{C}$ and $\mathrm{D}$. Hence, model $\mathrm{B}$ was selected as the model with the best fit to the data among all hypothesized models. Overall, model B shows good fit to the data as follows: $\chi^{2}=788.763, p<.001 ; \chi^{2}$ I $\mathrm{df}=2.586 ;$ GFI $=.932 ;$ SRMR $=.0454$; RMSEA $=.044$ 
(a) Model A

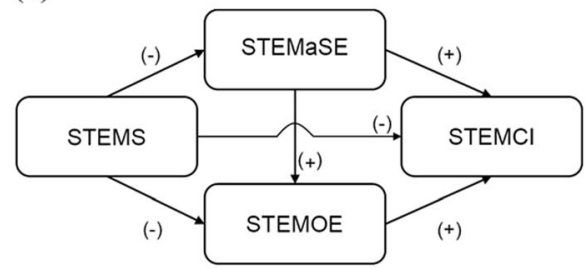

(c) Model C:

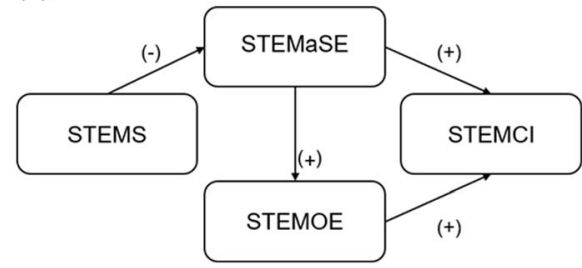

(b) Model B

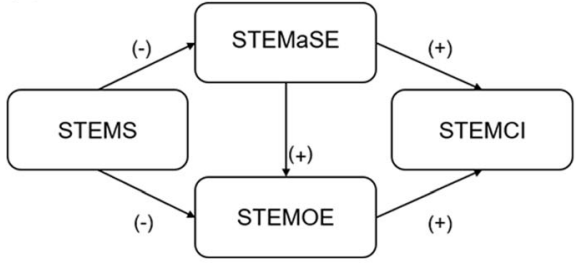

(d)Model D:

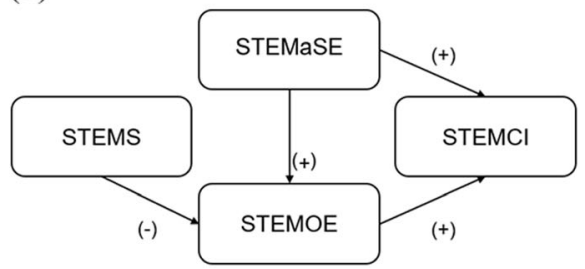

Fig. 3 Four models tested in the study

(90\% CI [.040, .048]); NFI = .931; CFI = .956; IFI = .956; and TLI $=.949$ (see Table 3$)$. A depiction of model B is presented in Fig. 4.

As shown in Table 4 and Fig. 4, students' STEM stereotypes are negatively related to their STEM selfefficacy (standardized coefficient $=-.21$ ) and STEM career-related outcome expectations (standardized coefficient $=-.19)$. Moreover, STEM self-efficacy is positively predictive of STEM career-related outcome expectations (standardized coefficient $=.30$ ) and STEM career interest (standardized coefficient $=.38$ ). STEM career-related outcome expectations are also positively predictive of STEM career interest, with a standardized coefficient of .30 .

The standardized total indirect effect of STEM stereotypes on STEM career interest was - .155. The bootstrapped total indirect effect of STEM stereotypes on STEM career interest was - .194 (95\% confidence interval $[\mathrm{CI}]=-.276,-.126), p<.01$. The bootstrapped indirect effect of STEM stereotypes on STEMCI via STEMaSE (STEMCI $\leftarrow$ STEMaSE $\leftarrow$ STEM stereotypes) was - .099 (95\% confidence interval $[\mathrm{CI}]=-.156,-$ $.057), p<.01$. The bootstrapped indirect effect of STEM stereotypes on STEMCI via STEMOE (STEMCI $\leftarrow$ STEMOE $\leftarrow$ STEM stereotypes) was - .072 (95\% confidence interval $[\mathrm{CI}]=-.126,-.035), p<.01$. Additionally, the bootstrapped indirect effect of STEM stereotypes on STEMCI through STEMaSE and STEMOE (STEM $\mathrm{CI} \leftarrow \mathrm{STEMOE} \leftarrow \mathrm{STEMaSE} \leftarrow$ STEM stereotypes) was $.023(95 \%$ confidence interval $[\mathrm{CI}]=-.045,-.012), p<$ .001 . The results show that the total indirect effect and all three specific indirect paths of STEM stereotypes on STEMCI were significant.

\section{Discussion}

The goal of this study was to validate a model depicting the relationships among students' STEM stereotypes, self-efficacy in STEM activities, outcome expectations, and students' STEM career interest. The results demonstrated that students' stereotypical beliefs regarding STEM careers significantly and negatively predicted their self-efficacy in STEM activities and their STEM careerrelated outcome expectations. Furthermore, STEM stereotypes affect students' career interest indirectly through STEM self-efficacy and outcome expectations. The results show that stronger STEM stereotypes predict lower self-efficacy in STEM activities and STEM career-related outcome expectations, which are related to lower interest in STEM fields. These findings provide crucial evidence explaining how students' perceptions of STEM careers and professionals further influence their career intentions.

Table 3 Fit indices of the SEM structural models $(n=824)$

\begin{tabular}{|c|c|c|c|c|c|c|c|c|c|c|c|c|c|}
\hline \multirow[t]{2}{*}{ 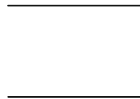 } & \multirow[t]{2}{*}{$x^{2}$} & \multicolumn{6}{|c|}{ Absolute fit indices } & \multicolumn{4}{|c|}{ Incremental fit indices } & \multicolumn{2}{|c|}{ Parsimony fit indices } \\
\hline & & $\overline{D f}$ & $p$ & $x^{2} / \mathrm{df}$ & GFI & SRMR & RMSEA & $\overline{\mathrm{NFI}}$ & CFI & IFI & TLI & $\overline{\text { AGFI }}$ & AIC \\
\hline Model A & 785.805 & 304 & $p<.001$ & 2.585 & .932 & .0441 & .044 & .931 & .956 & .956 & .949 & .916 & 933.805 \\
\hline Model B & 788.763 & 305 & $p<.001$ & 2.586 & .932 & .0454 & .044 & .931 & .956 & .956 & .949 & .916 & 934.763 \\
\hline Model C & 810.860 & 306 & $p<.001$ & 2.650 & .930 & .0545 & .045 & .929 & .954 & .954 & .947 & .914 & 954.860 \\
\hline Model D & 815.850 & 306 & $p<.001$ & 2.666 & .930 & .0671 & .045 & .928 & .954 & .954 & .947 & .914 & 959.850 \\
\hline
\end{tabular}




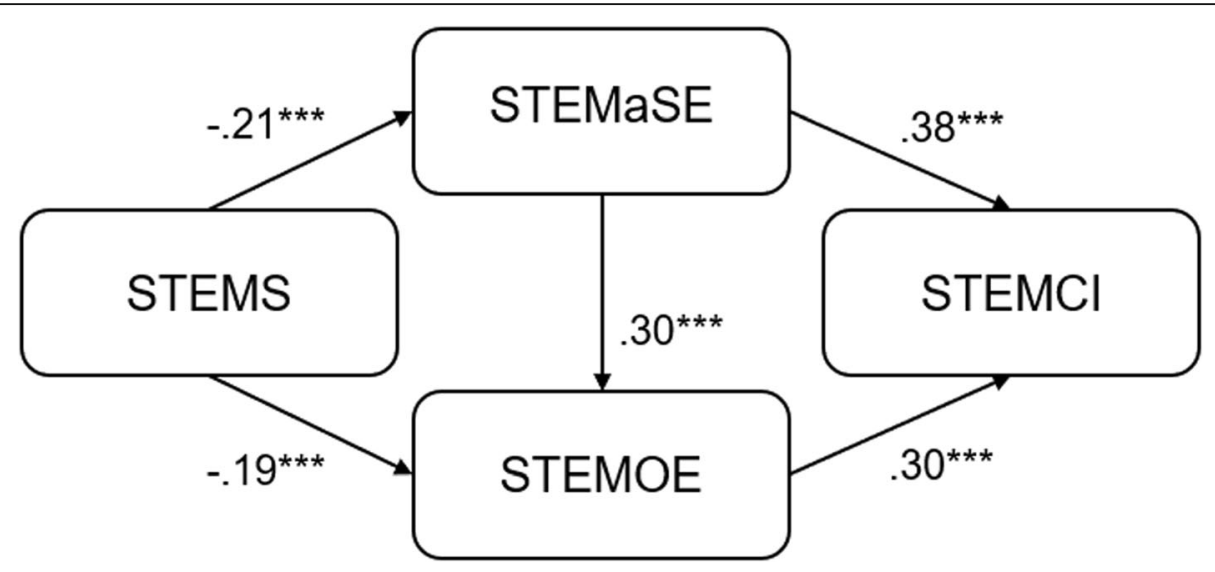

Fig. 4 Diagram and standardized path coefficients of the final SEM model (model B)

Effect of STEM stereotypes on career interest through self-efficacy in STEM activities and outcome expectations This study addresses a research gap and provides evidence showing that STEM stereotypes may have an impact on STEM career interest via both self-efficacy and outcome expectations. This finding is consistent with some of the findings reported in Garriott et al.'s (2016) study involving high school students showing that STEM stereotypes negatively predicted mathematics/science self-efficacy and that STEM stereotypes had no direct effect on career interest. In this study, the association between STEM stereotypes and students' self-efficacy (.21) was similar to that in the study by Garriott et al. (2016) $(-.15)$. This study supports that STEM stereotypes predict not only self-efficacy but also outcome expectations, which echoes the findings reported by Shen et al. (2014), which showed that internalized stereotypes predicted students' self-efficacy, outcome expectations, and career interest. However, according to Shen et al.'s (2014) results, internalized stereotypes directly affected students' interest in stereotypical occupations, which differed from the indirect effect observed in the present study. This difference may be explained by the distinction between STEM stereotypes used in this study and

Table 4 Results of the direct effects based on structural equation modelling

\begin{tabular}{|c|c|c|c|c|c|c|c|}
\hline & & & $\beta$ & B & S.E. & C.R. $^{a}$ & $p^{\mathbf{b}}$ \\
\hline STEMASE & $\leftarrow$ & STEM stereotypes & -.207 & -.157 & .032 & -4.983 & $* * *$ \\
\hline STEMOE & $\leftarrow$ & STEMaSE & .296 & .334 & .052 & 6.395 & *** \\
\hline STEMOE & $\leftarrow$ & STEM stereotypes & -.190 & -.163 & .036 & -4.536 & $* * *$ \\
\hline STEMCI & $\leftarrow$ & STEMaSE & .381 & .627 & .071 & 8.866 & $* * *$ \\
\hline STEMCI & $\leftarrow$ & STEMOE & .301 & .440 & .061 & 7.158 & *** \\
\hline
\end{tabular}

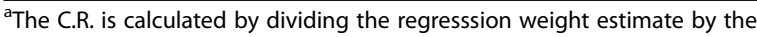
estimate of its standard error

$\mathrm{b}_{* * *} p<.001$ internalized cultural stereotypes used in Shen et al.'s (2014) study.

The indirect effects of STEM stereotypes on career interest could help explain why career-related interventions that successfully changed students' perceptions of STEM careers but sometimes do not influence their career aspiration (Archer et al., 2014). A plausible explanation is that a change in STEM stereotypes alone cannot have a direct effect on career interest. The findings indicate that to nurture students' interest in choosing STEM careers in the future, their perceived image of STEM professionals (related to STEM stereotypes) and the value of their work (career-related outcome expectations) are as important as their self-efficacy in STEM. The findings of this study suggest a way to intervene with students' STEM career interest by targeting STEM stereotypes, self-efficacy, and outcome expectations simultaneously. To transform the stereotypical image of STEM careers, educators could present the socialinteractive aspect of STEM professionals (e.g., scientists, engineers, and technicians) as ordinary people and describe how their work is related to people and society. In addition to eliminating students' STEM stereotypes, interventions also need to emphasize the importance of students' own capabilities in STEM practices to strengthen their self-efficacy through STEM activities.

\section{Relationships among self-efficacy in STEM activities, outcome expectations, and career interest}

This study also provides evidence validating the relationships among self-efficacy, outcome expectations and career interest from the STEM perspective. Most previous studies validating the SCCT model in STEM were conducted in the science, technology, engineering, or mathematics disciplines (Lent et al., 2018). Only a few studies explored the SCCT model in integrated STEM education (Garriott et al., 2016; Nugent et al., 2015). In this study, 
from a STEM integration perspective, self-efficacy in STEM activities significantly predicted the students' STEM career interest, which is similar to the findings of most studies in science, technology, engineering, or mathematics disciplines (Lent et al., 2018). However, Nugent et al.'s (2015) study (on students aged 10-14) found that when STEM was treated as science, technology, engineering, and mathematics disciplinary learning, self-efficacy had no significant direct effect on career orientation. Garriott et al. (2016) reported that high school students' mathematics/science self-efficacy was indirectly related to their mathematics/science career goals through mathematics/science interest. These discrepancies (direct versus indirect effects on career intentions) may be due to the differences in the measurement (i.e., measuring STEM self-efficacy in integrated STEM or disciplinary STEM), dependent variables (career interest or career intentions) or cultural contexts (i.e., Western and Eastern) or age ranges (i.e., upper elementary and high school) of the samples between Garriott et al.'s (2016) study and this study.

The results of this study highlight the importance of introducing elementary students to integrated STEM education. The findings suggest that self-efficacy in STEM activities is crucial for elementary students' interest in entering STEM fields in the future. In previous studies validating the effect of self-efficacy on career interest/intention in STEM education, the constructs of STEM self-efficacy were represented by self-efficacy in mathematics (Franz-Odendaal et al., 2020; O'Brien et al., 1999; Wang, 2013), science (Sasson \& Cohen, 2013), mathematics and science (Garriott et al., 2017; Navarro et al., 2007; Sahin et al., 2017), or STEM as disciplinary learning (Nugent et al., 2015). Especially because the measurement of STEM self-efficacy did not explicitly mention the concept of STEM in this study, the results show that engaging in STEM activities has a substantial influence on career interest, not simply due to the nominal linkage between "STEM activities" and "STEM careers". Specifically, STEM activities have the potential to provide career-related information and experiences based on which students could develop their selfefficacy, which could help them build their STEM career interest.

\section{Limitations and future research}

This study focused on four key constructs in the overlapping fields of STEM learning and career development. However, a limitation of this study is that many other individual level, classroom-level, school-level, and family-level factors, were not included in the model. Future studies could explore the roles played by educator, peer, school, and family contextual factors within the framework of this study. Students' achievement (e.g., in mathematics and science) could also be a potential key influential or outcome factor in the model. Moreover, future researchers could consider adding disciplinary STEM self-efficacy to the proposed model to evaluate the extent to which it could supplement the effect of integrated STEM self-efficacy on career interest.

Career development is a life-long, dynamic process. This study was a cross-sectional investigation providing an overview of the psychoeducational status of upperelementary students. The proposed model could be modified for use with other age groups. In addition, this study could not capture the dynamic interactions among the variables. The perceptions of students, such as STEM stereotypes, are believed to change due to students' learning and other social interactions. Longitudinal studies could provide more information regarding how these variables change as students' age and determining the relationships among these variables could be an important step forward.

\section{Conclusions}

This study shows the effect of elementary students' STEM stereotypes could have on their STEM career interest through self-efficacy and outcome expectations. The findings highlight the often-neglected role of students' stereotypes in students' career development in STEM fields. Moreover, for the first time, this study confirmed that students' self-efficacy in STEM activities has a positive influence on their STEM career interest. Educators should pay attention to students' stereotypes regarding STEM careers and attempt to transform stereotypical conceptions of STEM careers into more realistic and diversified conceptions. In addition, the developed instruments (STEMaSE, STEMOE, and STEMCI) exhibited good reliability and validity. These instruments could serve as valuable measurement tools in STEM education.

\section{Abbreviations}

AGFI: Adjusted goodness-of-fit index; AlC: Akaike information criterion; CFA: Confirmatory factor analysis; CFI: Comparative fit index; Cl: Career interest; EFA: Exploratory factor analysis; GFI: Goodness-of-fit index;

IFI: Incremental fit index; KMO: Kaiser-Meyer-Olkin; MASS: Math and Science Stigma; NFI: Normed fit index; OE: Outcome expectations;

SRMR: Standardized root mean square residual; RMSEA: Root mean square error of approximation; SCCT: Social cognitive career theory; S.E.: Standard error; SE: Self-efficacy; SEM: Structural Equation Modelling; STEM: Science, Technology, Engineering, and Mathematics; STEMaSE: Self-efficacy in STEM activities; STEMCI: STEM career interest; STEMOE: STEM outcome expectations; TLI: Tucker-Lewis index

\section{Supplementary Information}

The online version contains supplementary material available at https://doi. org/10.1186/s40594-021-00295-y.

Additional file 1: Appendix 1. Instruments used in this study

Additional file 2: Appendix 2. Descriptives of and correlations among the four constructs 


\section{Acknowledgements}

Not applicable.

\section{Authors' contributions}

$\mathrm{TL}$ contributed to the conception and design of the study; led data collection, analysis, and interpretation; and writing and revising the manuscript. WWMS contributed to the design of the study, data collection and interpretation, and revising the manuscript. ZHW contributed to the design of the study, data analysis and interpretation, and revising the manuscript. WCL contributed to the design of the study and revising the manuscript. All authors read and approved the final manuscript.

\section{Funding}

Not applicable.

\section{Availability of data and materials}

The datasets analysed during the current study are not publicly available due to the request made in the consent forms issued to participants.

\section{Declarations}

\section{Ethics approval and consent to participate}

The research study reported in this article was approved by the Education University of Hong Kong. In keeping with the Education University of Hong Kong requirements, participants were provided informed consent.

\section{Consent for publication}

Not applicable.

\section{Competing interests}

The authors declare that they have no competing interests.

\section{Author details}

${ }^{1}$ Department of Science and Environmental Studies and Centre for Education in Environmental Sustainability, The Education University of Hong Kong, 10 Lo Ping Road, Tai Po, Hong Kong, People's Republic of China. ${ }^{2}$ Department of Curriculum and Instruction, The Education University of Hong Kong, Tai Po, Hong Kong, People's Republic of China.

Received: 21 October 2020 Accepted: 29 April 2021

Published online: 17 May 2021

\section{References}

Allison, P. D. (2003). Missing data techniques for structural equation modeling. Journal of Abnormal Psychology, 112(4), 545-557. https://doi.org/10.1037/ 0021-843X.112.4.545.

Archer, L., DeWitt, J., \& Dillon, J. (2014). 'It didn't really change my opinion': exploring what works, what doesn't and why in a school science, technology, engineering and mathematics careers intervention. Research in Science \& Technological Education, 32(1), 35-55. https://doi.org/10.1080/0263 5143.2013.865601.

Archer, L., DeWitt, J., Osborne, J., Dillon, J., Willis, B., \& Wong, B. (2013). 'Not girly, not sexy, not glamorous': primary school girls' and parents' constructions of science aspirations 1. Pedagogy, Culture and Society, 21(1), 171-194. https:// doi.org/10.1080/14681366.2012.748676.

Bandura, A. (1977). Self-efficacy: toward a unifying theory of behavioral change. Psychological Review, 84(2), 191-215. https://doi.org/10.1037/0033-295X.84.2.1 91.

Bandura, A. (1986). Social foundations of thought and action. Englewood Cliffs: Prentice Hall.

Bentler, P. M., \& Bonett, D. G. (1980). Significance tests and goodness of fit in the analysis of covariance structures. Psychological Bulletin, 88(3), 588-606. https:// doi.org/10.1037/0033-2909.88.3.588.

Betz, N. E. (2008). Advances in vocational theories. Handbook of Counseling Psychology, 4, 357-374.

Blotnicky, K. A., Franz-Odendaal, T., French, F., \& Joy, P. (2018). A study of the correlation between STEM career knowledge, mathematics self-efficacy, career interests, and career activities on the likelihood of pursuing a STEM career among middle school students. International Journal of STEM Education, 5(1), 1-15.
Browne, M. W., \& Cudeck, R. (1993). Alternative ways of assessing model fit. In K. A. Bollen, \& J. S. Long (Eds.), Testing structural equation model, (pp. 136-162). Newbury Park: Sage.

Capobianco, B. M., Diefes-Dux, H. A., Mena, I., \& Weller, J. (2011). What is an engineer? Implications of elementary school student conceptions for engineering education. Journal of Engineering Education, 100(2), 304-328. https://doi.org/10.1002/j.2168-9830.2011.tb00015.x.

Cheryan, S., Siy, J. O., Vichayapai, M., Drury, B. J., \& Kim, S. (2011). Do female and male role models who embody STEM stereotypes hinder women's anticipated success in STEM? Social Psychological and Personality Science, 2(6), 656-664. https://doi.org/10.1177/1948550611405218.

Child, D. (2006). The Essentials of Factor Analysis. 3rd edn. New York: Continuum.

DeWitt, J., Archer, L., \& Osborne, J. (2013). Nerdy, brainy and normal: children's and parents' constructions of those who are highly engaged with science. Research in Science Education, 43(4), 1455-1476. https://doi.org/10.1007/s11165-012-9315-0.

Diekman, A. B., Brown, E. R., Johnston, A. M., \& Clark, E. K. (2010). Seeking congruity between goals and roles: a new look at why women opt out of science, technology, engineering, and mathematics careers. Psychological Science, 21(8), 1051-1057. https://doi.org/10.1177/0956797610377342.

Education Bureau, Hong Kong. (2016). Driving STEM education - developing creative potential. Available at: http://www.edb.gov.hk/attachment/tc/ curriculum-development/renewal/STEM/STEM\%200verview_c.pdf.

Fralick, B., Kearn, J., Thompson, S., \& Lyons, J. (2009). How middle schoolers draw engineers and scientists. Journal of Science Education and Technology, 18(1), 60-73. https://doi.org/10.1007/s10956-008-9133-3.

Franz-Odendaal, T. A., Blotnicky, K. A., \& Joy, P. (2020). Math self-efficacy and the likelihood of pursuing a STEM-based career: a gender-based analysis. Canadian Journal of Science, Mathematics, and Technology Education, 20(3), 538-556. https://doi.org/10.1007/s42330-020-00105-7.

Fung, Y. Y. H. (2002). A comparative study of primary and secondary school students' images of scientists. Research in Science \& Technological Education, 20(2), 199-213. https://doi.org/10.1080/0263514022000030453.

Garriott, P. O., Hultgren, K. M., \& Frazier, J. (2016). STEM stereotypes and high school students' math/science career goals. Journal of Career Assessment, 25(4), 585-600

Garriott, P. O., Raque-Bogdan, T. L., Zoma, L., Mackie-Hernandez, D., \& Lavin, K. (2017). Social cognitive predictors of Mexican American high school students' math/science career goals. Journal of Career Development, 44(1), 77-90. https://doi.org/10.1177/0894845316633860.

Gottfredson, L. S. (1981). Circumscription and compromise: a developmental theory of occupational aspirations. Journal of Counseling Psychology, 28(6), 545-579. https://doi.org/10.1037/0022-0167.28.6.545.

Hair, J. F. (2006). Multivariate data analysis. Pearson Education India.

Hancock, A. J., Clarke, H. M., \& Arnold, K. A. (2020). Sexual orientation occupational stereotypes. Journal of Vocational Behavior, 119, 103427. https:// doi.org/10.1016/j.jvb.2020.103427.

Hazari, Z., Sonnert, G., Sadler, P. M., \& Shanahan, M. C. (2010). Connecting high school physics experiences, outcome expectations, physics identity, and physics career choice: a gender study. Journal of Research in Science Teaching, 47(8), 978-1003.

Holmegaard, H. T., Madsen, L. M., \& Ulriksen, L. (2014). To choose or not to choose science: Constructions of desirable identities among young people considering a STEM higher education programme. International Journal of Science Education, 36(2), 186-215. https://doi.org/10.1080/09500693.2012.749362.

Hu, L. T., \& Bentler, P. M. (1999). Cutoff criteria for fit indexes in covariance structure analysis: Conventional criteria versus new alternatives. Structural Equation Modeling: A Multidisciplinary Journal, 6(1), 1-55. https://doi.org/10.1 080/10705519909540118

Japan Society for STEM Education. (2018). Practice cases: education for children to solve creative problems. Retrieved January 11, 2019, from https://www.jstem.jp/features/interview_201809/

Johnson, C. C. (2013). Conceptualizing integrated STEM education. School Science and Mathematics, 113(8), 367-368. https://doi.org/10.1111/ssm.12043.

Jöreskog, K. G., \& Sörbom, D. (1996). LISREL 8: user's reference guide. Lincolnwood: Scientific Software International.

Kier, M. W., Blanchard, M. R., Osborne, J. W., \& Albert, J. L. (2014). The development of the STEM career interest survey (STEM-CIS). Research in Science Education, 44(3), 461-481. https://doi.org/10.1007/s11165-013-9389-3.

Kline, R. B. (2005). Methodology in the social sciences. London: Routledge.

Lachapelle, C. P., Phadnis, P., Hertel, J., \& Cunningham, C. M. (2012). What is engineering? A survey of elementary students. Washington, DC: Paper presented at 2nd P-12 engineering and design education research summit. 
Lent, R., Brown, S., \& Hackett, G. (1994). Toward a unifying social cognitive theory of career and academic interest, choice, and performance. Journal of Vocational Behavior, 45(1), 79-122. https://doi.org/10.1006/jvbe.1994.1027.

Lent, R., Miller, M., Smith, P., Watford, B., Hui, K., \& Lim, R. (2015). Social cognitive model of adjustment to engineering majors: longitudinal test across gender and race/ethnicity. Journal of Vocational Behavior, 86, 77-85. https://doi.org/1 0.1016/j.jvb.2014.11.004.

Lent, R. W., Brown, S. D., \& Hackett, G. (2000). Contextual supports and barriers to career choice: a social cognitive analysis. Journal of Counseling Psychology, 47(1), 36-49. https://doi.org/10.1037/0022-0167.47.1.36

Lent, R. W., Brown, S. D., Hackett, G., \& Brown, D. (2002). Social cognitive career theory. Career choice and development, 4, 255-311.

Lent, R. W., Sheu, H. B., Miller, M. J., Cusick, M. E., Penn, L. T., \& Truong, N. N. (2018). Predictors of science, technology, engineering, and mathematics choice options: a meta-analytic path analysis of the social-cognitive choice model by gender and race/ethnicity. Journal of Counseling Psychology, 65(1) 17-35. https://doi.org/10.1037/cou0000243.

Lin, C., \& Deemer, E. D. (2019). Stereotype threat and career goals among women in STEM: Mediating and moderating roles of perfectionism. Journal of Career Development. https://doi.org/10.1177/0894845319884652.

Luo, T., Li, J., \& So, W. W. M. (2018). Analysis of students' visual presentations of STEM professionals. Hualien: Paper presented at 2018 International Conference of East-Asian Association for Science Education.

Luo, T., So, W. W. M., Li, W. C., \& Yao, J. (2020). The development and validation of a survey for evaluating primary students' self-efficacy in STEM activities. Journal of Science Education and Technology. https://doi.org/10.1007/s10956020-09882-0.

Marginson, S., Tytler, R., Freeman, B., \& Roberts, K. (2013). STEM: country comparisons: International comparisons of science, technology, engineering and mathematics (STEM) education. Final report. Melbourne: Australian Council of Learned Academies.

Masnick, A. M., Valenti, S. S., Cox, B. D., \& Osman, C. J. (2010). A multidimensional scaling analysis of students' attitudes about science careers. International Journal of Science Education, 32(5), 653-667. https://doi.org/10.1080/ 09500690902759053.

Matsumoto, D. E. (2009). The Cambridge dictionary of psychology. Cambridge: Cambridge University Press.

Metcalf, H. (2010). Stuck in the pipeline: a critical review of STEM workforce literature. InterActions: UCLA Journal of Education and Information Studies, 6(2), $1-20$.

Milner, D. I., Horan, J. J., \& Tracey, T. J. (2014). Development and evaluation of STEM interest and self-efficacy tests. Journal of Career Assessment, 22(4), 642653. https://doi.org/10.1177/1069072713515427.

Nassar-McMillan, S. C., Wyer, M., Oliver-Hoyo, M., \& Schneider, J. (2011). New tools for examining undergraduate students' STEM stereotypes: implications for women and other underrepresented groups. New Directions for Institutional Research, 2011(152), 87-98. https://doi.org/10.1002/ir.411.

National Research Council (2014). STEM integration in K-12 education: Status, prospects, and an agenda for research. Washington, DC: National Academies Press.

Navarro, R. L., Flores, L. Y., \& Worthington, R. L. (2007). Mexican American middle school students' goal intentions in mathematics and science: a test of social cognitive career theory. Journal of Counseling Psychology, 54(3), 320-335. https://doi.org/10.1037/0022-0167.54.3.320

Nugent, G., Barker, B., Grandgenett, N., \& Adamchuk, V. I. (2010). Impact of robotics and geospatial technology interventions on youth STEM learning and attitudes. Journal of Research on Technology in Education, 42(4), 391-408. https://doi.org/10.1080/15391523.2010.10782557.

Nugent, G., Barker, B., Welch, G., Grandgenett, N., Wu, C. R., \& Nelson, C. (2015). A model of factors contributing to STEM learning and career orientation. International Journal of Science Education, 37(7), 1067-1088. https://doi.org/1 0.1080/09500693.2015.1017863.

O'Brien, V., Martinez-Pons, M., \& Kopala, M. (1999). Mathematics self-efficacy, ethnic identity, gender, and career interests related to mathematics and science. The Journal of Educational Research, 92(4), 231-235. https://doi.org/1 0.1080/00220679909597600.

Office of the Chief Scientist (2014). Science, technology, engineering and mathematics: Australia's future. Australian Government.

Oh, Y. J., Jia, Y., Lorentson, M., \& LaBanca, F. (2013). Development of the educational and career interest scale in science, technology, and mathematics for high school students. Journal of Science Education and Technology, 22(5), 780-790. https://doi.org/10.1007/s10956-012-9430-8.

Organization for Economic Co-operation and Development (OECD) (2008). Encouraging student interest in science and technology studies. Global Science Forum. Retrieved from the internet December 9, 2019: https://www. oecd.org/publications/encouraging-student-interest-in-science-andtechnology-studies-9789264040892-en.htm

Pedhazur, E. J. (1997). Multiple regression in behavioral research: explanation and prediction. New York: Thompson Learning, Inc.

Sadler, P. M., Sonnert, G., Hazari, Z., \& Tai, R. (2012). Stability and volatility of STEM career interest in high school: a gender study. Science Education, 96(3), 411427. https://doi.org/10.1002/sce.21007.

Sahin, A., Ekmekci, A., \& Waxman, H. C. (2017). Collective effects of individual, behavioral, and contextual factors on high school students' future STEM career plans. International Journal of Science and Mathematics Education, 16, 1-21. https://doi.org/10.1007/s10763-017-9847-x.

Sasson, I., \& Cohen, D. (2013). Assessment for effective intervention: enrichment science academic program. Journal of Science Education and Technology, 22(5), 718-728. https://doi.org/10.1007/s10956-012-9425-5.

Schermelleh-Engel, K., Moosbrugger, H., \& Müller, H. (2003). Evaluating the fit of structural equation models: tests of significance and descriptive goodness-offit measures. Methods of Psychological Research Online, 8(2), 23-74.

Schreiber, J. B., Nora, A., Stage, F. K., Barlow, E. A., \& King, J. (2006). Reporting structural equation modeling and confirmatory factor analysis results: a review. The Journal of Educational Research, 99(6), 323-338. https://doi.org/1 0.3200/JOER.99.6.323-338.

Shen, F. C., Liao, K. Y., Abraham, W. T., \& Weng, C. (2014). Parental pressure and support toward Asian Americans' self-efficacy, outcome expectations, and interests in stereotypical occupations: living up to parental expectations and internalized stereotyping as mediators. Journal of Counseling Psychology, 61(2), 241-252. https://doi.org/10.1037/a0036219.

So, W. W. M., Zhan, Y., Chow, S. C. F., \& Leung, C. F. (2018). Analysis of STEM activities in primary students' science projects in an informal learning environment. International Journal of Science and Mathematics Education, 16(6), 1003-1023. https://doi.org/10.1007/s10763-017-9828-0.

van Aalderen-Smeets, S. I., Walma van der Molen, J. H., \& Xenidou-Dervou, I. (2018). Implicit STEM ability beliefs predict secondary school students' STEM self-efficacy beliefs and their intention to opt for a STEM field career. Journal of Research in Science Teaching, 56(4), 465-485.

van Tuijl, C., \& van der Molen, J. H. W. (2016). Study choice and career development in STEM fields: an overview and integration of the research. International Journal of Technology and Design Education, 26(2), 159-183. https://doi.org/10.1007/s10798-015-9308-1.

VandenBos, G. R., \& American Psychological Association (2015). APA dictionary of psychology, (2nd ed., ). Washington, DC: American Psychological Association.

Wang, X. (2013). Why students choose STEM majors. American Educational Research Journal, 50(5), 1081-1121. https://doi.org/10.3102/00028312134 88622.

Wheaton, B. (1987). Assessment of fit in overidentified models with latent variables. Sociological Methods \& Research, 16(1), 118-154. https://doi.org/1 $0.1177 / 0049124187016001005$.

Zimmerman, B. J. (2000). Self-efficacy: an essential motive to learn. Contemporary Educational Psychology, 25(1), 82-91. https://doi.org/10.1006/ceps.1999.1016.

\section{Publisher's Note}

Springer Nature remains neutral with regard to jurisdictional claims in published maps and institutional affiliations. 